\title{
Uso inadecuado y excesivo de antibióticos: Salud pública y salmonicultura en Chile
}

\author{
ANA MILLANAO B., ${ }^{1, a}$, MARCELA BARRIENTOS H., ${ }^{1, a}$, CAROLINA GÓMEZ C ${ }^{1, a}$, \\ ALEXANDRA TOMOVA ${ }^{2, \mathrm{~b}}$, ALEJANDRO BUSCHMANN ${ }^{3, \mathrm{c}}$, \\ HUMBERTO DÖLZ ${ }^{1, a, d}$, FELIPE C. CABELLO ${ }^{2}$
}

\section{Injudicious and excessive use of antibiotics: Public health and salmon aquaculture in Chile}

Salmon aquaculture was one of the major growing and exporting industries in Chile. Its development was accompanied by an increasing and excessive use of large amounts of antimicrobials, such as quinolones, tetracyclines and florfenicol. The examination of the sanitary conditions in the industry as part of a more general investigation into the uncontrolled and extensive dissemination of the ISA virus epizootic in 2008, found numerous and wide-ranging shortcomings and limitations in management of preventive fish health. There was a growing industrial use of large amounts of antimicrobials as an attempt at prophylaxis of bacterial infections resulting from widespread unsanitary and unhealthy fish rearing conditions. As might be expected, these attempts were unsuccessful and this heavy antimicrobial use failed to prevent viral and parasitic epizootics. Comparative analysis of the amounts of antimicrobials, especially quinolones, consumed in salmon aquaculture and in human medicine in Chile robustly suggests that the most important selective pressure for antibiotic resistant bacteria in the country will be excessive antibiotic use in this industry. This excessive use will facilitate selection of resistant bacteria and resistance genes in water environments. The commonality of antibiotic resistance genes and the mobilome between environmental aquatic bacteria, fish pathogens and pathogens of terrestrial animals and humans suggests that horizontal gene transfer occurs between the resistome of these apparently independent and isolated bacterial populations. Thus, excessive antibiotic use in the marine environment in aquaculture is not innocuous and can potentially negatively affect therapy of bacterial infections of humans and terrestrial animals.

(Rev Med Chile 2011; 139: 107-118).

Key words: Antibacterial agents; Antibacterial drug resistance; Fisheries.

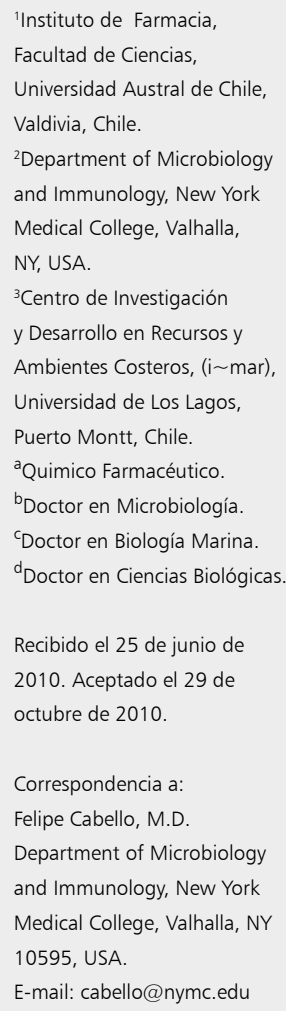

"La fe en el poder mágico de las drogas terapéuticas llega a convertirse en una histeria de masas, que aletarga por igual la capacidad crítica de los científicos y de los legos".

René Dubos en Mirage of Health. Utopia, progress and biological change

\begin{abstract}
T a historia de la microbiología revela que su comienzo fue el resultado de la búsqueda de soluciones para problemas sociales y económicos que aquejaban a Francia y Alemania ${ }^{1-3}$. En el caso de Pasteur, sus estudios sobre la fermentación, sobre las parasitosis y las virosis de los gusanos de seda, solucionaron serios problemas de la vitivinicultura y de la agricultura que limitaban notoriamente su éxito económico ${ }^{1-3}$. A su vez, los estímulos para los estudios de Koch fueron la gran mortalidad
\end{abstract}


que provocaba el ántrax en animales domésticos, y la tuberculosis y el cólera en las poblaciones humanas de Alemania ${ }^{1-3}$. Similarmente, al comienzo de la introducción de los antibacterianos como armas terapéuticas en la medicina en las décadas de 1930 y 1940, fueron las observaciones clínicas y de laboratorio de una serie de infectólogos norteamericanos, como W. McDermott, M. Finland, L. Weinstein y otros ${ }^{4-7}$ que, extendiendo los conceptos microbiológicos elaborados por Pasteur y Koch a la terapia racional de las enfermedades infecciosas bacterianas, desarrollaron los conceptos fundamentales del uso de estas substancias terapéuticas para la medicina humana y la animal ${ }^{4-7}$, transformando dramática y positivamente la evolución de las enfermedades bacterianas, con repercusiones sociales y económicas ${ }^{7-9}$.

Como queda ilustrado por estos ejemplos, desde sus orígenes la microbiología y la infectología han tenido una relación recíproca y dinámica con el ambiente social y económico en el que se desarrollan y desenvuelven ${ }^{1-3,7,9}$. La relación ha demostrado ser mutuamente beneficiosa para el desarrollo de la microbiología y la infectología como para la ciencia y la sociedad a la que están llamadas a servir ${ }^{7,9}$. Sin embargo, la polémica nacional e internacional aún en curso, suscitada por el excesivo uso de antibióticos en la acuicultura del salmón en Chile ${ }^{10-17}$, pone de manifiesto la anacrónica y nociva fisura que existe en nuestro país entre las actividades científicas, como la microbiología y la infectología, y las políticas de salud pública y de salud animal ${ }^{10-17}$.

Con el objetivo de avanzar más en la comprensión y en las proyecciones sanitarias de estos problemas, en esta revisión discutiremos nuevos hallazgos respectos del uso de antibacterianos en la acuicultura del salmón en Chile e información reciente respecto del potencial intercambio de genes de resistencia entre bacterias del ambiente marino, patógenos de peces, patógenos humanos y de animales terrestres. Ello será analizado a la luz del conocimiento microbiológico e infectológico aplicado al uso racional de antibacterianos. Conjuntamente, analizaremos la potencial relevancia de esta información para entender el creciente y negativo fenómeno de resistencia bacteriana en Chile y su potencial impacto para la salud animal y humana. Esta información no ha sido presentada o discutida en publicaciones previas de estos $u$ otros autores.

\section{Uso industrial de antibióticos en la crianza de animales}

En la década de 1960 autores como T. Watanabe y E.S. Anderson, N. Datta, H.W.Smith en Japón e Inglaterra respectivamente, basados en trabajos previos de J. Lederberg, demostraron la trasmisión horizontal de los genes de resistencia a antibióticos de manera epidémica entre diferentes poblaciones y especies bacterianas, incluyendo patógenos animales y humanos ${ }^{18-28}$. Estos trabajos plantearon claramente que el uso de antibióticos en la crianza industrial de animales repercutía negativamente sobre la salud humana y animal, generando bacterias zoonóticas resistentes a los antibióticos ${ }^{23-28}$, y facilitaba además la transferencia de los genes de resistencia a antibióticos desde las bacterias del ambiente animal a patógenos humanos ${ }^{23-28}$.

Posteriormente, este trabajo pionero ha recibido amplia confirmación a través de una serie de estudios como, por ejemplo, con las infecciones humanas por Campylobacter jejuni y Escherichia coli uropatogénica resistentes a las quinolonas y originadas en aves ${ }^{29-31}$, las infecciones por Salmonella resistentes a antibacterianos originadas en ganado vacuno ${ }^{32}$, y las infecciones por Staphylococcus aureus resistentes a la meticilina originadas en cerdos, entre muchos otros ejemplos ${ }^{33}$. Por estas razones se ha desarrollado una importante corriente de pensamiento en microbiología e infectología destinada a restringir y regular el uso de antibióticos en la crianza industrial de animales, en Europa y Norteamérica ${ }^{34-37}$. Un corolario de esto son los esfuerzos de la OMS para prohibir el uso en animales, incluyendo la acuicultura, de los antibióticos de gran utilidad en medicina humana como las quinolonas ${ }^{37,38}$.

\section{Antibióticos, resistencia y profilaxis}

La introducción de los antibacterianos al arsenal terapéutico en medicina humana, en la década de 1930 con el uso de las sulfas, y posteriormente a la medicina veterinaria en la década de 1940, a poco andar encontró que además de las milagrosas curas que estas drogas producían, su uso indiscriminado se acompañaba de complicaciones que debilitaban, y que aun trabajaban en contra de sus éxitos terapéuticos ${ }^{4-6,39,40}$. Los fundamentales trabajos de laboratorio de S. Luria y M. Delbruck (Premios Nobel de Medicina, 1969) y del matri- 
monio Lederberg (Esther y Joshua [Premio Nobel de Medicina, 1958]) demostraron en EE. UU. en las décadas de 1940 y 1950 que la resistencia bacteriana a antimicrobianos y a los bacteriófagos es seleccionada por la presencia de éstos, actuando sobre bacterias previamente resistentes generadas por mutaciones espontáneas ${ }^{41-43}$. Ellos establecieron una relación causal y directa, en el marco de la Teoría de la Evolución, respecto de la presencia de antibióticos y la selección de bacterias resistentes, señalando que, a mayor uso de antibióticos, la presión selectiva sobre las poblaciones bacterianas resistentes se intensifica, adquiriendo una ventaja selectiva sobre las bacterias susceptibles ${ }^{41-44}$.

La introducción terapéutica de los antibacterianos fue instantáneamente seguida de la aparición de bacterias resistentes a ellos y de fracasos terapéuticos, como ocurrió con el uso único de la estreptomicina y de la isoniazida en el tratamiento de la tuberculosis ${ }^{4-6,44}$ y el uso de la penicilina $G$ en el tratamiento de infecciones estafilocócicas ${ }^{4-6,44}$. Estas investigaciones establecieron también que la presencia de bacterias resistentes a los antibióticos está relacionada con la cantidad de ellos usados en un determinado espacio geográfico, ya sea este hospital, región o país ${ }^{4-46}$. El entusiasmo despertado por las "curas milagrosas" producidas por los antibacterianos estimuló su uso en la profilaxis de diversas patologías. La utilidad de su uso profiláctico para situaciones bien determinadas se estableció a través del tiempo, como en la prevención de la enfermedad reumática y de la endocarditis bacteriana $\mathrm{a}^{47-50}$.

Sin embargo, su uso masivo y continuado a nivel poblacional en la prevención de enfermedades bacterianas se desacreditó en corto tiempo ${ }^{47-53}$. Por ejemplo, el uso masivo de sulfas para prevenir la fiebre reumática en planteles militares de EE.UU. durante la Segunda Guerra fue acompañado por la aparición de epidemias de estreptococos resistentes a las sulfas, sin una disminución de la frecuencia de la escarlatina y de la enfermedad reumática ${ }^{48,49}$. La validez de las limitaciones y de los resultados negativos de la profilaxis masiva con antibacterianos, se extendieron a la medicina veterinaria ${ }^{20-22}$.

Estudios sobre estos problemas en medicina veterinaria estimularon una investigación de la Cámara de los Lores, en el Reino Unido, que en 1969 evacuó un informe al respecto ${ }^{54}$. Este informe, llamado "informe Swann", señaló que el uso excesivo de antibióticos en animales conduce a riesgos potenciales para la salud humana y animal, sugiriendo, además, que su utilización debiera ser restringida y regulada ${ }^{54}$. La evidencia acumulada respecto de los aspectos negativos del uso indiscriminado de antibacterianos en terapéutica y en profilaxis en medicina humana y veterinaria condujo en la mayoría de los países de Europa y de Norteamérica a la restricción y regulación de su uso para situaciones clínicas específicas y a su prescripción por personal autorizado.

\section{¿Existe intercambio genético entre bacterias de los ambientes acuáticos y terrestres?}

Existen publicaciones sugiriendo que el uso de antibióticos en la acuicultura carecería de los efectos deletéreos para la salud humana y animal que tiene su uso en la crianza industrial de animales terrestres ${ }^{55,56}$. Sin embargo, el hecho de que bacterias del ambiente terrestre y acuático compartan unidades de intercambio genético llamadas mobilomas y que incluyen secuencias de inserción (IS), secuencias de inserción comunes (ISCR) transposones, islas genómicas, casetas de $\mathrm{ADN}$, integrones y plásmidos, concordante con la universalidad del material genético, hacen esta posición insostenible ${ }^{57-61}$. El amplio intercambio genético, probablemente bidireccional, entre bacterias de los ambientes acuáticos y terrestres estaría siendo demostrado por la evidencia de que bacterias acuáticas, patógenos de peces y patógenos humanos, comparten ampliamente los mismos determinantes genéticos de resistencia a antibióticos $^{62-66}$.

Esta evidencia demostraría que las bacterias del ambiente acuático no están aisladas de las bacterias del ambiente terrestre y que las bacterias de ambos ecosistemas comparten información genética probablemente a través de la transferencia horizontal de genes mediada por diversos mecanismos que transfieren variados elementos genéticos ${ }^{57-61}$. Por ejemplo, el elemento genético de resistencia a antibióticos SXT/R391, capaz de conjugación e integración en el cromosoma bacteriano, se encuentra ampliamente distribuido en los patógenos humanos Vibrio cholera, Providencia y Proteus, del patógeno de peces Photobacterium damselae subs piscicida y en la bacteria marina Shewanella ${ }^{67-70}$. Los genes transferibles de resistencia a las quinolonas qnr que han aparecido últimamente en patógenos humanos como Escherichia coli, Salmonella, V. 
cholerae y Klebsiella, aparentemente se originaron en bacterias marinas como Vibrio y Shewanella y se encuentran también presentes en otras bacterias marinas (Figura 1) ${ }^{71,72}$. Plásmidos de amplio rango de huésped, probablemente originados en el ambiente acuático y que confieren resistencia a antibacterianos como estreptomicina, tetraciclina, sulfa y trimetoprim, son compartidos por los patógenos humanos Yersinia pestis, Salmonella y el patógeno de peces Yersinia ruckeri, como resultado de intercambios genéticos aparentemente recientes ${ }^{73,74}$.

Además, el concepto últimamente introducido de resistoma ${ }^{75-77}$, que indica que patógenos de animales y humanos adquieren genes de resistencia de una colección de genes de resistencia presentes en bacterias ambientales, los cuales incorporan a su pan genoma, hacen poco probable la excepcionalidad del ambiente acuático respecto de estos problemas $^{77-81}$. Dada la universalidad del material genético, tampoco existen razones biológicas para sustentar la hipótesis de que el intercambio genético entre bacterias de estos ambientes es unidireccional. Por ejemplo, de aguas costeras y de peces de Chile se pueden cultivar bacterias de la flora humana, normal y patológica ${ }^{82,83}$, y en los sedimentos existen residuos de antibióticos con potencial para estimular la variación y el intercambio genético y la recombinación (Buschmann y Cabello, observaciones no publicadas, $\left.{ }^{84}\right)$. Otras publicaciones recientes han resaltado el rol importante que juegan los ambientes acuáticos en el flujo y en la evolución de los genes de resistencia bacteriana ${ }^{59,85}$.

\section{Volúmenes de antibióticos usados en la salmonicultura y sus implicaciones}

El colapso sanitario de la salmonicultura, producido por epizootias provocadas por el piojo del mar (Caligus rogercresseyi) y el virus ISA, dejó al desnudo las quebrantadas condiciones higiénicas de la salmonicultura en Chile y reveló una de las razones por la cual el uso de antibióticos en ella parece ser excesivo e imprudente ${ }^{86-88}$. Estas defectuosas condiciones sanitarias, que favorecen la aparición y la diseminación de infecciones en los peces, incluyen excesiva densidad de peces en las jaulas, demasiada cercanía de las jaulas entre ellas y a tierra firme, estrés por la excesiva e inadecuada manipulación de los peces e incorrecta disposición de peces muertos y de desechos. Recientemente, a raíz de este problema sanitario, han comenzado a fluir cifras respecto de las cantidades de antibacterianos usados en la salmonicultura chilena ${ }^{89}$.

De acuerdo a la información entregada oficialmente por el Ministerio de Economía de Chile en julio de 2009, durante los años 2007 y 2008 se usaron en la salmonicultura en Chile 385 y 325 toneladas de antibióticos, respectivamente ${ }^{89}$. De estas cantidades informadas, los años 2007 y 2008 , se utilizaron 149 y 57 toneladas de las quinolonas ácido oxolínico y flumequina, respectivamente. El resto del tonelaje correspondió a antibióticos tales como la tetraciclina y el florfenicol ${ }^{89}$. Un informe autorizado del año 2008, difundido en el sitio web de la compañía Marine Harvest (uno de los mayores productores de salmón en Chile), reconoció

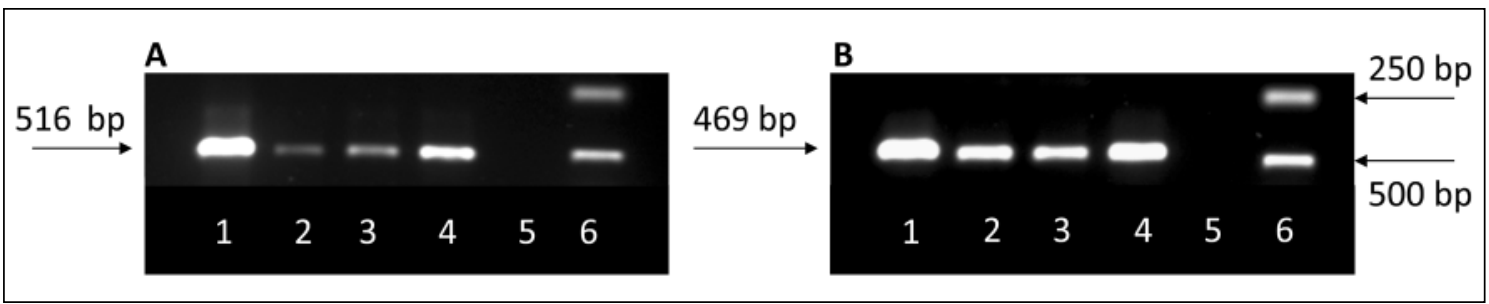

Figura 1. Presencia de los genes plasmidiales de resistencia a las quinolonas, qnrA y qnrB, en bacterias de sedimentos marinos de la Décima Región, Chile y en Eschericha coli aisladas de orina infectada de pacientes en Puerto Montt, Décima Región, Chile. A. Amplicones del gene qnrA (516 bp) fueron obtenidos por la amplificación con RPC con partidores descritos en la referencia 100. 1. Control positivo, ADN pMG252; 2 . Marinobacter sp; 3. Epsilon Proteobacterium; 4. Escherichia coli clínica N 6; 5 . Control negativo, E. coli DH5 $\alpha$; 6. Marcadores de ADN de peso molecular. B. Amplicones del gene qnrB (469 bp) fueron obtenidos con partidores descritos en la referencia 100. 1. Control positivo, ADN pMG298; 2. Rhodococcus sp 25; 3. Rhododococcus sp 26; 4. 3. E. coli clínica N 5; 5. Control negativo, E. coli DH5 $\alpha$; 6 . Marcadores de ADN de peso molecular. La determinación de especie de las bacterias marinas fue hecha comparando la secuencia de ADN de amplicones del gene del ARN ribosomal $16 \mathrm{~S}$ amplificado con RPC usando partidores ya descritos con secuencias en la base de datos GeneBank (101). El mismo procedimiento comparativo se usó para confirmar la secuencia de ADN de los amplicones qnrA y qnrB. 
que en los años 2007 y 2008 esta firma usó en Noruega 0,02 y 0,07 gramos de antibióticos por cada tonelada de salmón producida, respectivamente ${ }^{90}$. Según el mismo informe, durante los años 2007 y 2008, Marine Harvest usó en Chile 732 y 560 gramos de antibióticos por cada tonelada de salmón producida, respectivamente ${ }^{90}$. Estos datos indican que el año 2007 Marine Harvest usó en Chile por cada tonelada de salmón producida 36.600 veces más antibióticos que en Noruega y en el año 2008, 8.000 veces más $s^{90}$. Estas diferencias en el uso de antibióticos por la misma compañía industrial, en Chile y en Noruega, indicarían importantes divergencias en la calidad del manejo sanitario de la salmonicultura en los dos países. Además, indican contrastes en la regulación del uso de antibacterianos por el Estado de Chile y de Noruega, responsables de esta ineludible y esencial tarea de salud pública ${ }^{90}$. Estas cifras parecieran sugerir también que las diferencias de uso de antibióticos entre Chile y Noruega son incluso superiores a las que se obtienen con las cifras provistas por el Ministerio de Economía de Chile ${ }^{89,90}$.

Como se indica en los párrafos precedentes, las estadísticas del Ministerio de Economía sugerían que en Chile el año 2007 se usaron aproximadamente 600 veces más antibióticos que en Noruega para producir una tonelada de salmón y estas estimaciones sobrepasan cifras consideradas hace algunos años que indicaban que en Chile se usarían en la salmonicultura 70 a 300 veces más antibacterianos que en Noruega ${ }^{91}$. Nuestras propias investigaciones tienden a corroborar estas cifras $^{92-94}$. La Figura 2 ilustra la relación existente

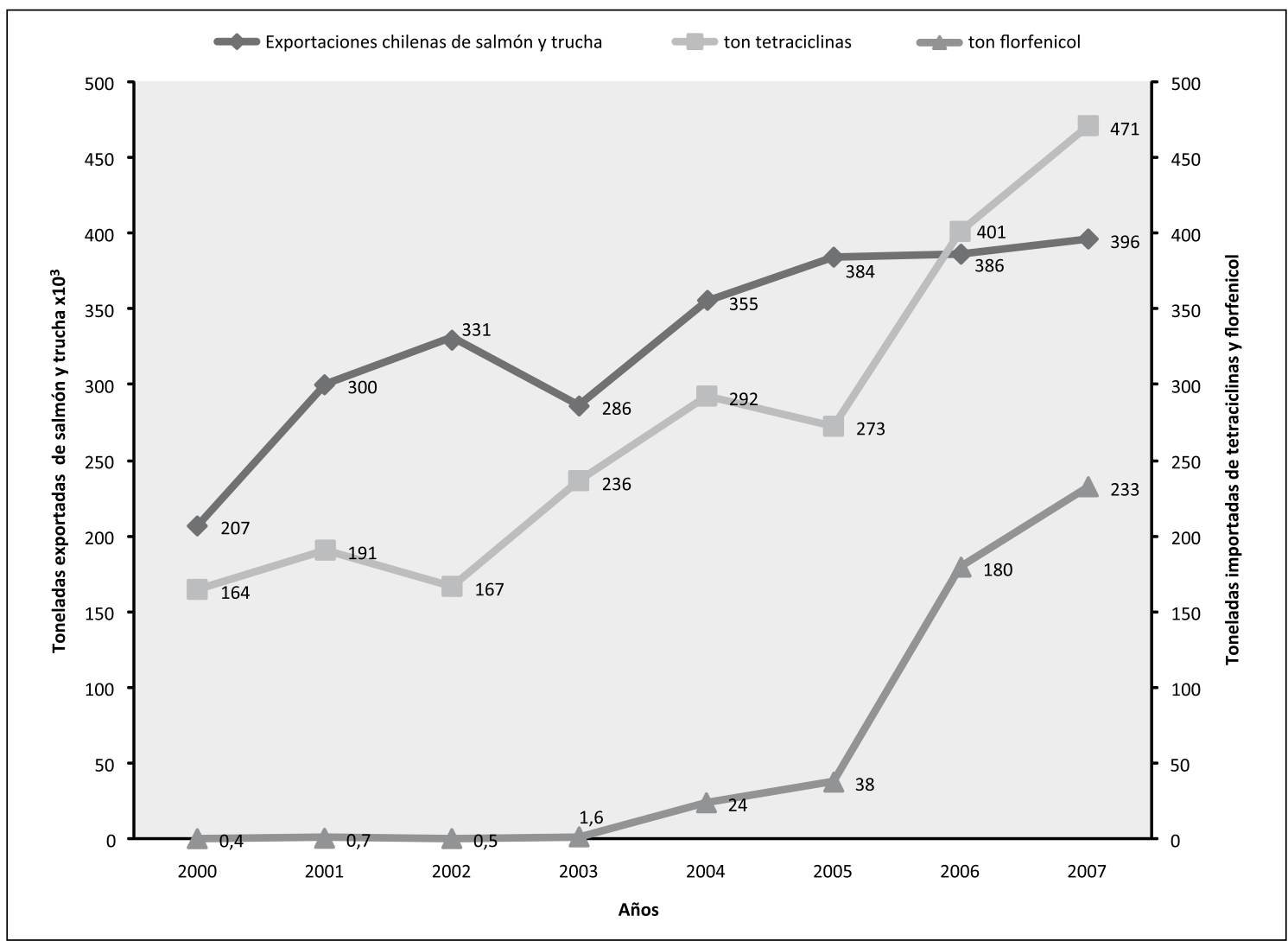

Figura 2. Toneladas métricas de salmón y trucha exportadas y toneladas netas de tetraciclinas y florfenicol importadas para uso en medicina veterinaria en Chile durante el período 2000 a 2007. La información presentada en las Figuras 2, 3, 4 y 5 ha sido obtenida de la base de datos Macroscope ${ }^{\circledR}$, de las fuentes de datos de la Cámara de Comercio de Santiago, del Servicio Agrícola y Ganadero, y del Instituto de Salud Pública, como está descrito en las referencias 92-94. Las toneladas netas de salmón y trucha exportados son datos publicados por SalmónChile. 


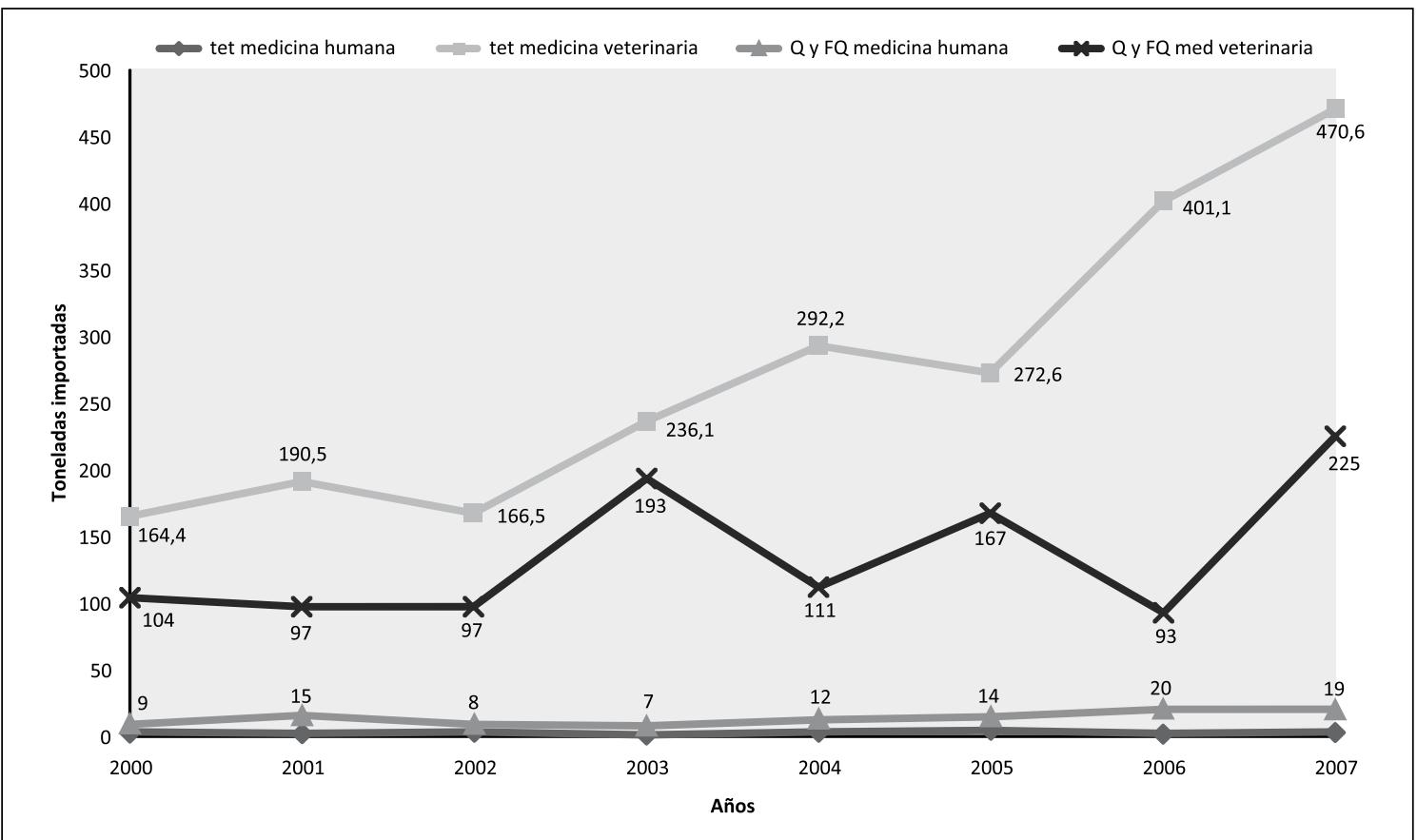

Figura 3. Tetraciclinas (tet), quinolonas $(\mathrm{Q})$ y fluoroquinolonas $(\mathrm{FQ})$ importadas para medicina humana y medicina veterinaria en Chile durante el período 2000 a 2007. Los datos fueron obtenidos de las referencias 92-94.

entre el aumento de la exportación de salmón y de trucha y el aumento de las importaciones de los antibióticos florfenicol y tetraciclinas para medicina veterinaria. Estos antibióticos, y especialmente el florfenicol, son usados primaria y extensivamente en la salmonicultura en Chile y el aumento de la importación de antibióticos para uso veterinario al país corresponde en gran medida al crecimiento de la salmonicultura ${ }^{92-94}$.

La Figura 3 muestra que el aumento de las cantidades de tetraciclinas y quinolonas importadas a Chile para uso en medicina veterinaria, incluyendo la salmonicultura, exceden con creces la importación de estos mismos antimicrobianos para uso en medicina humana ${ }^{92-94}$. La Figura 4 ilustra que las cantidades de quinolonas importadas mayoritariamente en Chile son aquellas usadas en la acuicultura del salmón, como el ácido oxolínico y flumequina y en bastante menor cantidad el enrofloxacino y el norfloxacino, los cuales se utilizan en otros sectores de medicina veterinaria ${ }^{92-94}$.

Un análisis de las cifras en la Figura 4 también indica que de las 1.193 toneladas de quinolonas usadas en Chile en esos 8 años, 958 toneladas correspondieron a ácido oxolínico y flumequina, quimioterápicos usados solamente en la salmonicultura ${ }^{92-94 .}$ Ciprofloxacino, la fluoroquinolona más utilizada en medicina humana, es análoga

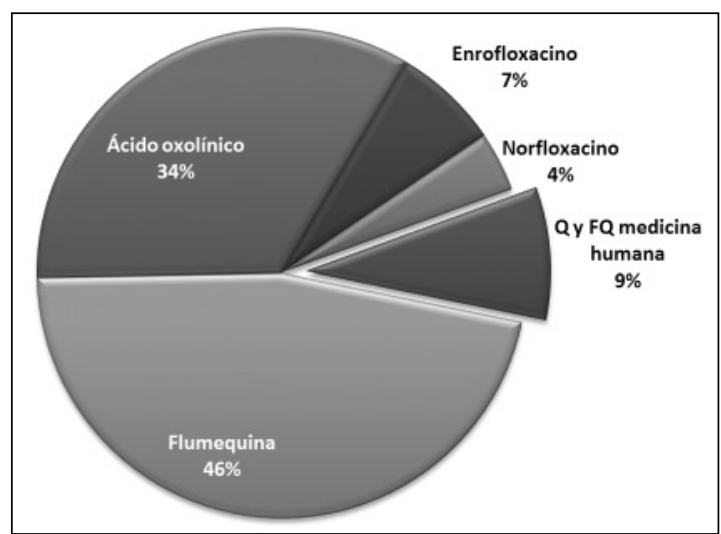

Figura 4. Distribución porcentual de la importación de 1193 toneladas métricas de quinolonas y fluoroquinolonas para uso en medicina humana y medicina veterinaria en Chile durante el período 2000 a 2007. Los datos fueron obtenidos de las referencias 92-94. 


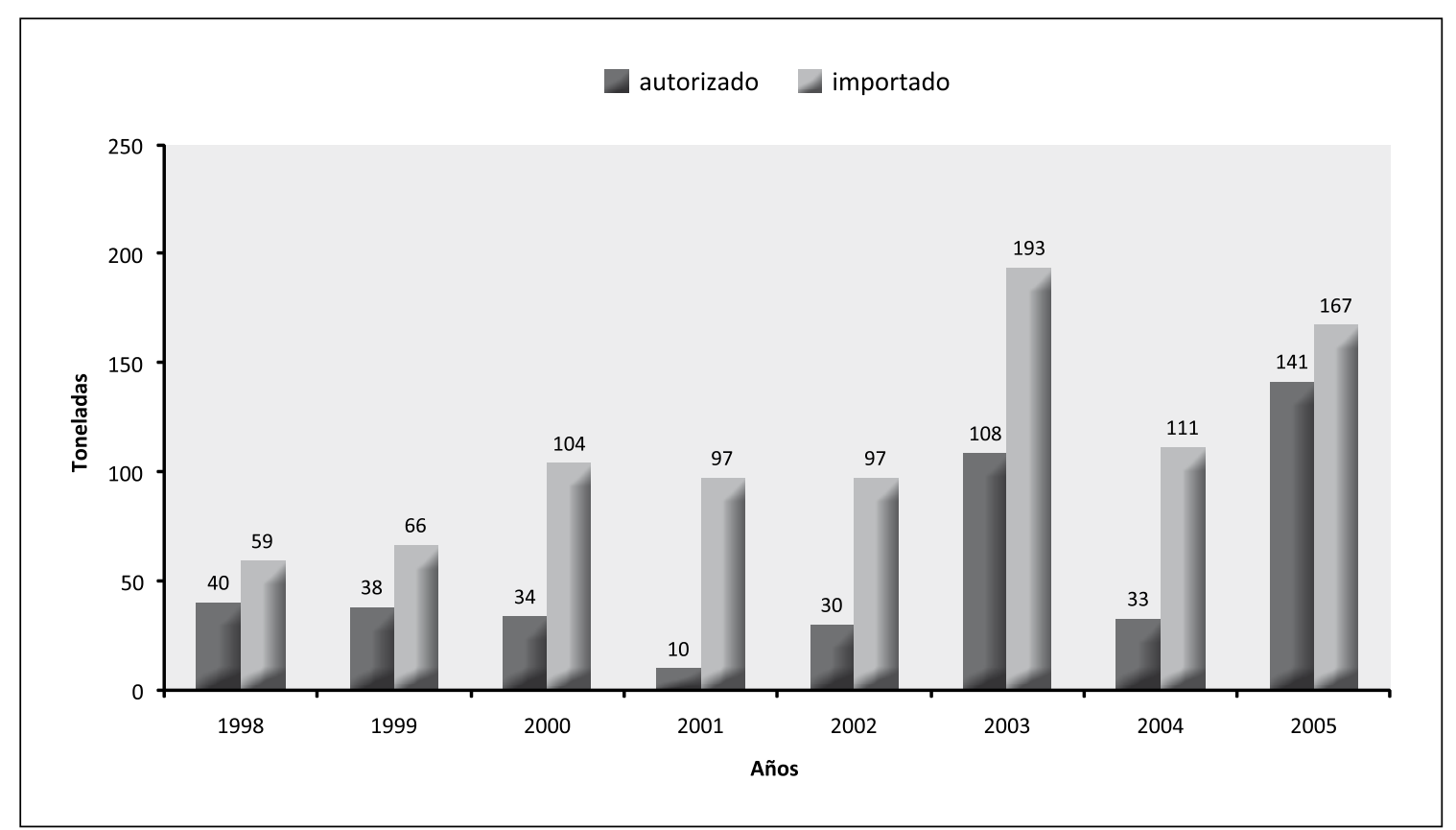

Figura 5. Relación entre la cantidad de quinolonas y fluoroquinolonas autorizadas para uso y disposición por el Servicio Agrícola Ganadero y la cantidad de quinolonas importadas para medicina veterinaria en Chile durante el período 1998 a 2005. Los datos fueron obtenidos de las referencias 92-94.

estructural de la flumequina y ambas son capaces de seleccionar resistencias cruzadas a otras quinolonas $^{92}$. Además, como lo ilustra la Figura 5, una proporción de los antimicrobianos importados para animales en Chile, incluyendo salmones, escapa del proceso de autorización de uso y de disposición por el Servicio Agrícola Ganadero (SAG) y por ende de la contabilización de este uso por los organismos del Estado encargados de su control ${ }^{92-94}$. Tal observación sugiere que las cantidades de antibióticos usadas en la salmonicultura puedan ser aún mayores que las registradas en nuestras fuentes de información.

Para apreciar mejor la dimensión de las cantidades de antibióticos usadas en la salmonicultura, conviene destacar que en Chile se reguló y restringió el uso de antibióticos en medicina humana desde el año 1998 y que se usan aproximadamente solo 19 toneladas de quinolonas al año en ella (Figura 3$)^{92-94}$. Este análisis indicaría que las precarias condiciones sanitarias de la salmonicultura chilena pudieron temporalmente ser prevenidas gracias al excesivo uso metafiláxico, profiláctico y terapéutico de los antibióticos y por las condiciones de la alta y prístina calidad medioambiental donde se desarrollaba la industria. Los antibióticos, al ser empleados de manera profiláctica, prevenían temporalmente epizootias bacterianas; pero, como era de esperar, fueron completamente incapaces de prevenir las epizootias parasitarias y virales ${ }^{86-87}$.

La rápida y ruinosa diseminación de la epizootia por virus ISA, precedida por un aumento de las infestaciones por piojo del mar, y su estela de pérdidas económicas, incluyendo la cesantía de importantes sectores de la población, era un fenómeno previsible y, por lo tanto, era prevenible. Esta evidencia ilustra, a nuestro juicio, una vez más el paradigma de que el uso incorrecto de antibióticos en profilaxis masivas es incapaz de reemplazar al adecuado manejo sanitario de las poblaciones humanas y animales en la prevención de las enfermedades ${ }^{47-49}$.

\section{Conclusiones}

Nuestro análisis resalta que -en Chile- el uso de antibióticos en la crianza industrial de ani- 
males, incluyendo la salmonicultura, constituye probablemente la mayor presión selectiva para la selección de genes de resistencia a antibióticos y de bacterias resistentes a ellos en el territorio nacional (Figuras 2, 3 y 4). Esto es especialmente cierto para la selección de resistencia a las quinolonas, el grupo de antibióticos todavía de gran efectividad para tratar infecciones por patógenos humanos y animales ${ }^{37,38}$. Según directivas recientes de la Organización Mundial de la Salud, este grupo de antibióticos debería ser reservado para tratar solamente infecciones en humanos y su uso en la producción animal para alimentos debiera ser totalmente restringido ${ }^{37,38}$.

En el caso de la salmonicultura en Chile, la presión selectiva producida por este gran volumen de ellos es amplificada, porque hasta hace poco tiempo este volumen se usaba en un área geográfica reducida de la costa de la X Región, la que constituía el locus geográfico de esta actividad ${ }^{95,96}$. Este excesivo e intensivo uso de los antibióticos en la salmonicultura, además de tener los negativos resultados descritos para la evolución de esta industria, puede potencialmente expresar resultados negativos para la salud humana y los equilibrios biológicos del ambiente acuático ${ }^{97-99}$. De la información presentada se desprende que el excesivo uso de antibacterianos en la acuicultura del salmón en Chile seleccionará y propenderá a la diseminación de genes de resistencia y de bac-

\section{Tabla 1. Medidas destinadas a disminuir y a estudiar el impacto del uso de antibacterianos en la salmonicultura}

\section{Medidas sanitarias y epidemiológicas}

- Mejorar las condiciones higiénicas y sanitarias de la salmonicultura

- Establecer barreras que eviten la diseminación de patógenos entre los sitios de salmonicultura

- Mejorar el diagnóstico de enfermedades bacterianas, virales y parasitarias de peces

- Establecer y registrar la susceptibilidad a antibacterianos de patógenos de peces y de bacterias autóctonas y foráneas al ambiente acuático

- Regular y registrar los volúmenes de antibacterianos importados y usados en medicina veterinaria, incluyendo la salmonicultura, como se realiza en medicina humana

- Investigar la presencia de antibacterianos en el ambiente terrestre y acuático, viviente e inanimado, donde se realiza crianza industrial de animales

- Educar a todo el personal que trabaja en la salmonicultura sobre el uso adecuado de antibacterianos, los problemas generados por la profilaxis antibacteriana y por la resistencia a antibacterianos

\section{Medidas de investigación}

- Comparar la frecuencia de la resistencia a antibacterianos usados en la acuicultura con la que emerge en la flora normal y patógena en la comunidad y en hospitales de la X Región.

- Determinar si existen diferencias respecto de las frecuencias y de las características de la resistencia a las quinolonas, a las tetraciclinas y al florfenicol entre patógenos humanos de la X Región y otras regiones del país

- Determinar la presencia de bacterias resistentes a los antibacterianos en el sedimento marino y la columna de agua en lugares donde se ha realizado salmonicultura y en lugares de control. Relacionarlos con la presencia de residuos de antibacterianos en el ambiente animal e inanimado

- Estudiar la transferencia horizontal de genes de resistencia de bacterias acuáticas a bacterias terrestres y viceversa, incluyendo patógenos animales y humanos, para trazar el flujo de los genes de resistencia

- Con el mismo propósito, identificar en estas bacterias los mecanismos genéticos de resistencia (plásmidos, integrones, transposones, elementos SXT) y determinar su secuencia de ADN

- Analizar la presencia de bacterias resistentes en la flora normal faríngea, intestinal y cutánea de operarios responsables de la manipulación de alimentos para peces con antibacterianos, y también las de sus familias

- Desarrollar modelos oceanográficos de barreras y control epidemiológico de patógenos de peces

- Estudiar potenciales reservorios naturales y antrópicos de patógenos de peces 
terias resistentes entre los ambientes acuáticos y los terrestres, impactando negativamente la salud animal y humana ${ }^{93-99}$.

Situaciones de crisis, como la descrita en esta revisión, abren también la puerta a oportunidades para solucionarlas en beneficio de todas las partes comprometidas. En este caso, la solución de ella requiere un esfuerzo mancomunado, educacional y amplio de los organismos del Estado, los empresarios y los trabajadores de la industria y los profesionales entendidos en estos problemas y sus organizaciones. Estos esfuerzos son necesarios para difundir el conocimiento sobre el uso adecuado de los antimicrobianos, su implementación moderna y dinámica en el desarrollo de la industria acuícola y otras industrias de crianza industrial de animales, protegiendo concomitantemente la salud humana, la salud animal y el medio ambiente. La Tabla 1 presenta algunas acciones futuras necesarias para enfrentar este problema de una manera racional y ajustada al conocimiento moderno microbiológico, infectológico y de salud pública. De esta forma se produciría el consorcio virtuoso y beneficioso entre ciencia, técnica, sociedad y el aparato productivo. Consorcio cuya fertilidad fuera tan bien demostrada por Pasteur y Koch hace ya 150 años y por la introducción de los antibacterianos a la medicina humana y veterinaria a mediados del Siglo XX.

Agradecimientos: Felipe C. Cabello, agradece a la Fundación John Simon Guggenheim por una beca para estudiar el problema discutido en el comentario y a las Srtas. Luz María Fariña y Virginia Díaz, de la organización Terram, por información periodística. A don Patricio Igor, de la organización Ecoceanos, por información periodística. F. C. C. y Alejandro H. Buschmann agradecen al Lenfest Ocean Program/Pew Charitable Trusts por fondos para estudiar el problema discutido en esta revisión. Humberto Dölz y Ana Millanao, agradecen el apoyo del Laboratorio GSK Chile. Agradecemos al Dr. Luis Martínez M., del Hospital Universitario Marqués de Valdecilla, Santander, España por las cepas E. coli J53 con plásmidos pMG252 y pGM298 conteniendo los genes qnrA y qnrB1, respectivamente. La Dra. María Luisa Rioseco, del Hospital Regional de Puerto Montt, nos proporcionó las E. coli aisladas de orina. F. C. C. agradece a la Dra. Katia Velásquez por indicaciones al texto.

\section{Referencias}

1. Walker MEM. Pioneers of public health. Oliver and Boyd. Edinburgh, 1930.

2. Sigerist HE. The great doctors. New York: WW Norton Co. Inc, 1933.

3. Winslow CEA. The Conquest of Epidemic Disease. A Chapter in the History of Ideas. New York: Hafner Publishing Company, 1967.

4. Mc Dermott W. Antimicrobial therapy. Third William Allen Pusey Memorial Lecture. Presented at The Institute of Medicine of Chicago and the Chicago Society of Internal Medicine, October 28, 1949. Proc Inst Med Chic 1950; 18: 2-12.

5. Finland $\mathrm{M}$. The present status of antibiotics in bacterial infections. Bull N Y Acad Med 1951; 27: 199-220.

6. Weinstein L. The complications of antibiotic therapy. Bull N Y Acad Med 1955; 31: 500-18.

7. Mc Dermott W, Rogers DE. Social ramifications of control of microbial disease. Johns Hopkins Med J 1982; 151: 303-12.

8. Dowling HF. Fighting Infection. Conquest of the Twenty Century. Cambridge, MA: Harvard University Press, 1977.

9. Krasner RI. The Microbial Challenge. Science, Disease and Public Health. $2^{\text {nd }}$ Edition. Boston: Jones and Bartlett Publishers, 2010.

10. Dölz H. Consideraciones sobre el empleo de la quimioterapia antibacteriana en la salmonicultura. Actualidad Farmacéutica 1992; 49: 7-9.

11. Dölz H. La resistencia de las bacterias patógenas a los antimicrobianos, un fenómeno en avance que requiere urgente atención. Pharmakon 1999; 1: 14-21.

12. Cabello FC. 2004. [Antibiotics and aquaculture in Chile: Implications for human and animal health]. Rev Med Chile 2004; 132: 1001-6.

13. Cabello FC. Heavy use of prophylactic antibiotics in aquaculture: a growing problem for human and animal health and for the environment. Environ Microbiol 2006; 8: 1137-44.

14. Barrionuevo A. Salmon virus indicts Chile's fishing methods. New York Times. March 27, 2008.

15. Barrionuevo A. Chile's antibiotic use on salmon farms dwarfs that of top rival's. New York Times. Julio 27, 2009.

16. Burridge L, Weis JS, Cabello F, Pizarro J, Bostick K. Chemical use in salmon aquaculture: A review of current practices and possible environmental effects. Aquaculture 2010; 306: 7-23.

17. Barton JR, Fløysand A. The political ecology of Chilean salmon aquaculture, 1982-2010: A trajectory 
from economic development to global sustainability. Global Environ. Change (2010), doi:10.1016/j.gloenvcha.2010.04.001.

18. Mäkelä PH, Lederberg J, Lederberg EM. Patterns of sexual recombination in enteric bacteria. Genetics 1962; 47: 1427-39.

19. Watanabe T. Infective heredity of multiple drug resistance in bacteria. Microbiol Rev 1963; 27: 87-115.

20. Anderson ES. Origin of transferable drug-resistance factors in the Enterobacteriaceae. BMJ 1965; 2: 1289-91.

21. Datta N. Infectious drug resistance. Br Med Bull 1965; 21: 254-9.

22. Smith HW, Halls S. Observations on infective drug resistance in Britain. BMJ 1966; 1: 266-9.

23. Anderson ES. Drug resistance in Salmonella typhimurium and its implications. BMJ 1968; 3: 333-9.

24. Smith HW. Anti-microbial drugs in animal feeds. Nature 1968 ; 218: 728-31.

25. Smith HW. Effects of antibiotic on bacterial ecology in animals. Am J Nutr 1970; 23: 1472-9.

26. Datta N. Transferable antibiotic resistance in Escherichia coli. Proc Roy Soc Med 1971; 64: 533-4.

27. Smith HW. Antibiotic-resistant bacteria in animals: the dangers to human health. Br Vet J 1974; 130: 110-9.

28. Anderson ES. Transferable antibiotic resistance. BMJ 1968; 1: 574-5.

29. Smith KE, Besser JM, Hedberg CW, Leano FE T, Bender JB, Wicklund JH, et al. Quinolone-resistant Campylobacter jejuni infections in Minnesota, 1992-1998. N Engl J Med 1999; 340: 1525-32.

30. Johnson JR, Kuskowski MA, Menard M, Gajewski A, Xercavins M, Garau J. Similarity between human and chicken Escherichia coli isolates in relation to ciprofloxacin resistance status. J Infect Dis 2006; 194: 71-8.

31. Johnson JR, Sannes MR, Croy C, Johnston B, Clabots C, Kuskowski MA, et al. Antimicrobial drug-resistant Escherichia coli from humans and poultry products, Minnesota and Wisconsin, 2002-2004. Emerg Infect Dis 2007; 13: 838-46.

32. Spika JS, Waterman SH, Soo Hoo GW, St Louis ME, Pacer RE, James SM, et al. Chloramphenicol-resistant Salmonella newport traced through hamburger to dairy farms. N Engl J Med 1987; 316: 565-70.

33. Smith TC, Male MJ, Harper AL, Kroeger JS, Tinkler GP, Moritz ED, et al. Methicillin-resistant Staphylococcus aureus (MRSA) strain ST398 is present in Midwestern U.S. swine and swine workers. PLoS One 2009; 4: e4258.

34. Angulo FJ, Baker NL, Olsen SJ, Anderson A, Barrett TJ. Antimicrobial use in agriculture: Controlling the transfer of antimicrobial resistance to humans. Sem Ped Infect Dis 2004; 15: 78-85.
35. Prescott JF. History of antimicrobial usage in agriculture: On overview. En: Antimicrobial Resistance in Bacteria of Animal Origin. Aarestrup FM (ed).Washington, DC: ASM Press; 2006; 19-27.

36. Aarestrup FM, Wegener HC, Collignon P. Resistance in bacteria of the food chain: epidemiology and control strategies. Expert Rev. Anti Infect Ther 2008; 6: 733-50.

37. Collignon P, Powers JH, Chiller TM, Aidara-Kane A, Aarestrup FM. World Health Organization ranking of antimicrobials according to their importance in human medicine: A critical step for developing risk management strategies for the use of antimicrobials in food production animals. Clin Infect Dis 2009; 49: 132-41.

38. Heuer OE, Kruse H, Grave K, Collignon P, Karunasagar I, Angulo FJ. Human health consequences of use of antimicrobial agents in aquaculture. Clin Infect Dis 2009; 49: 1248-53.

39. Finland M. Changing ecology of bacterial infections as related to antibacterial therapy. J Infect Dis 1970; 122: 419-31.

40. Finland M. Emergence of antibiotic-resistant bacteria. N Engl J Med 1955; 253: 909-22.

41. Luria SE, Delbrück M. Mutations of bacteria from virus sensitivity to virus resistance. Genetics 1943; 28: 491-511.

42. Lederberg J, Lederberg EM. Replica plating and indirect selection of bacterial mutants. J Bacteriol 1952; 63: 399406.

43. Lederberg J. Replica plating and indirect selection of bacterial mutants: Isolation of preadaptive mutants in bacteria by sib selection. Genetics 1989; 121: 395-9.

44. Finland M. Emergence of antibiotic resistance in hospitals, 1935-1975. Rev Infect Dis 1979; 1: 4-22.

45. Levy SB. Factors impacting on the problem of antibiotic resistance. J Antimicrob Chemother 2002; 49: 25-30.

46. Levy SB, Marshall B. Antibacterial resistance worldwide: causes, challenges and responses. Nature Med 2004; 10 (Suppl): S122-9.

47. Finland M. Antibacterial agents: Uses and abuses in treatment and prophylaxis. Rhode Island Med J 1960; 43: 499-520.

48. Connor CAR. Experiences with rheumatic fever in the Army Air Forces. Am J Public Health 1946; 36: 236-43.

49. Billow BW, Albin MS. Observations on mass chemoprophylaxis with sulfadiazine. Ann Intern Med 1946; 24: 863-77.

50. Damrosch DS. Chemoprophylaxis and sulfonamide resistant streptococci. JAMA 1946; 130: 124-8.

51. Sandusky WR. Antibacterial agents in surgery. J Natl Med Assoc 1951; 43: 169-74.

52. Kuh C, Collen MF. Mass penicillin prophylaxis. JAMA 1949; 140: 1324-28. 
53. Hill TJ, Sims J, Newman M. The effects of penicillin dentifrice on the control of dental caries. J Dental Res 1953; 32: 448-52. (http://jdr.sagepub.com/content/32/4/448).

54. House of Lords - Science and Technology - Seventh Report. Select Committee on Science and Technology Seventh Report. Prudent use in animals. Chapter 3. December 2009. http://www.parliament.the-stationeryoffice.co.uk

55. Smith P, Hiney MP, Samuelsen OB. Bacterial resistance to antimicrobial agents used in fish farming: A critical evaluation of method and meaning. Ann Rev Fish Dis 1994; 4: 273-313.

56. Smith P. Antimicrobial resistance in aquaculture. Rev Sci Tech Off Int Epiz 2008; 27: 243-64.

57. Sørum H. Antimicrobial drug resistance in fish pathogens. En: Antimicrobial Resistance in Bacteria of Animal Origin. Aarestrup FM (ed), Washington, DC: ASM Press, 2006; 213-38.

58. Summers AO. Genetic linkage and horizontal gene transfer, the roots of the antibiotic multi-resistance problem. Animal Biotechnol 2006; 17: 125-35.

59. Van Elsas J, Bailey MJ. The ecology of transfer of mobile genetic elements. FEMS Microbiol Ecol 2002; 42: 187-97.

60. Norman A, Hansen LG, Sörensen SJ. Conjugative plasmids: vessels of the comunal gene pool. Phil Trans R Soc B 2009; 364: 2275-89.

61. Mazel D. Integrons: agents of bacterial evolution. Nature Rev Microbiol 2006; 4: 608-20.

62. Furushita M, Shiba T, Maeda T, Yahata M, Kaneoka A, Takahashi Y, et al. Similarity of tetracycline resistance genes isolated from fish farm bacteria to those from clinical isolates. Appl Environ Microbiol 2003; 69: 5336-42.

63. Macintosh D, Cunningham M, Ji B, Fekete FA, Parry EM, Clark SE, et al. Transferable, multiple antibiotic and mercury resistance in Atlantic Canadian isolates of Aeromonas salmonicida subsp. salmonicida is associated with carriage of an IncA/C plasmid similar to the Salmonella enterica plasmid pSN254. J Antimicrob Chemother 2008; 61: 1221-8.

64. Miranda CD, Kehrenberg C, Ulep C, Schwarz S, Roberts $\mathrm{MC}$. Diversity of tetracycline resistance genes in bacteria from Chilean salmon farms. Antimicrob Agents Chemother 2003; 47: 883-8.

65. Gordon L, Cloeckaert A, Doublet B, Schwarz S, BoujuAlbert A, Ganiére J-P, et al. Complete sequence of the floR-carrying multiresistance plasmid pAB5S9 from freshwater Aeromonas bestiarum. J Antimicrob Chemother 2008; 62: 65-71.

66. Rhodes G, Huys G, Swings J, McGann P, Hiney M, Smith P. Distribution of oxytetracycline resistance plasmids between aeromonads in hospital and aquaculture en- vironments: Implication of Tn1721 in dissemination of the tetracycline resistance determinant Tet A. Appl Environ Microbiol 2000; 66: 3883-90.

67. Pembroke JT, Piterina AV. A novel ICE in the genome of Shewanella putrefaciens W3-18-1: comparison with the SXT/R391 ICE-like elements. FEMS Microbiol Lett 2006; 264: 80-8.

68. Burrus V, Marrero J, Waldor MK. The current ICE age: Biology and evolution of SXT-related integrating conjugative elements. Plasmid 2006; 55: 173-83.

69. Osorio CR, Marrero J, Wozniak RAF, Lemos ML, Burrus V, Waldor MK. Genomic and functional analysis of ICEPdaSpa1, a fish-pathogen-derived SXT-related integrating conjugative element that can mobilize a virulence plasmid. J Bacteriol 2008; 190: 3353-61.

70. Wozniack RA, Waldor MK. Integrative and conjugative elements: mosaic mobile genetic elements. Enabling dynamic lateral gene flow. Nature Rev Microbiol 2010; 8: 552-63.

71. Poirel L, Liard A, Rodríguez-Martínez JM, Nordmann P. Vibrionaceae as a possible source of Qnr-like quinolone resistance determinants. J Antimicrob Chemother 2005; 56: 1118-21. Epub 2005 oct 14.

72. Poirel L, Rodríguez-Martínez JM, Mammeri H, Liard A, Nordmann P. Origin of plasmid-mediated quinolone resistance determinant QnrA. Antimicrob Agents Chemother 2005b; 49: 3523-25.

73. Welch TJ, Fricke WF, McDermott PF, White DG, Rosso M-L, Rasko DA, et al. Multiple antimicrobial resistance in plague: An emerging public health risk. PLoS ONE 2007; e309.

74. Fricke WF, Welch TJ, Mc Dermott PF, Mammel MK, Le Clerc JE, White DG, et al. Comparative genomics of the IncA/C multidrug resistance plasmid family. J Bacteriol 2009; 191: 4750-7.

75. D'Costa VM, Griffiths E, Wright GD. Expanding the soil antibiotic resistome: exploring environmental diversity. Curr Opin Microbiol 2007; 10: 481-9.

76. D'Costa VM, McGrann KM, Hughes DW, Wright GD. Sampling the antibiotic resistome. Science 2006; 311: 374-7.

77. Wright GD. The antibiotic resistome: the nexus of chemical and genetic diversity. Nat Rev Microbiol 2007; 5: 175-85.

78. Martínez JL. Environmental pollution by antibiotics and by antibiotic resistance determinants. Environ Poll 2009; 157: 2893-902.

79. Martínez JL. The role of natural environments in the evolution of resistance traits in pathogenic bacteria. Proc R Soc B 2009; 276: 2521-30.

80. Martínez JL. Antibiotics and antibiotic resistance genes 
in natural environments. Science. 2008; 321: 365-67.

81. Cantón R. Antibiotic resistance genes from the environment: a perspective through newly identified antibiotic resistance mechanisms in the clinical setting. Clin Microbiol Infect Dis 2009; 15 (Suppl 1): 20-5.

82. Silva J, Zemelman R, Mondaca MA, Henríquez M, Merino $\mathrm{C}$, González C. Antibiotic-resistant gram negative bacilli isolated from sea water and shellfish. Possible epidemiological implications. Rev Latinoam Microbiol 1987; 29: 165-9.

83. Miranda CD, Zemelman R. Antibiotic resistant bacteria in fish from the Concepción Bay, Chile. Mar Pollut Bull 2001; 42: 1096-102.

84. Couce A, Blázquez J. Side effects of antibiotics on genetic variability. FEMS Microbiol Rev 2009; 33: 531-8.

85. Baquero F, Martínez JL, Canton R. Antibiotics and antibiotic resistance in water environments. Curr Opin Biotechnol 2008; 19: 260-5.

86. Rozas M, Asencio G. Evaluación de la situación epidemiológica de la caligiasis en Chile; hacia una estrategia de control efectiva. SalmoCiencia 2007; No. 2: 43-59.

87. Godoy MG, Aedo A, Kibenge MJ, Groman DB, Yason $\mathrm{CV}$, Grothusen $\mathrm{H}$, et al First detection, isolation and molecular characterization of infectious salmon anaemia virus association with clinical disease in farmed Atlantic salmon (Salmo salar) in Chile. BMC Vet Res 2008; 4: 28.

88. Kibenge FS, Godoy MG, Wang Y, Libenge MJ, Gherardelli V, Mansilla $S$ et al. Infectious salmon anaemia virus (ISAV) isolated from the ISA disease outbreaks in Chile diverged from ISAV isolates from Norway around 1996 and was disseminated around 2005, based on surface glycoprotein gene sequences. Virol J 2009; 6: 88.

89. Ministerio de Economía de Chile. Carta Oficial a Oceana sobre la cantidad de antibióticos usados en la acuacultura del salmón en Chile. Julio 14, 2009.

90. Marin Harvest. Sustainability Report, 2008. http://www. marineharvest.com/Documents/Marine $\% 20$ Harvest $\% 20$ -\%20Sustainability\%20Report\%20-\%202008.pdf.

91. Bravo S, Dölz H, Silva MT, Lagos C, Millanao A, Urbina M. Diagnóstico del uso de fármacos y otros productos químicos en la acuicultura, 2003. http://www.fip.cl/FIP/ Archivos/pdf/informes/inffinal\%202003-28.pdf.

92. Millanao A. Estudio cualitativo y cuantitativo de las quinolonas y fluoroquinolonas importadas y autorizadas para uso y disposición en medicina y en veterinaria en Chile, en el período 1998-2001. Consideraciones sobre su impacto para la salud pública y el medio ambiente. Tesis de Grado. Escuela de Química y Farmacia. Universidad Austral de Chile, 2002. http://cybertesis.uach.cl/ tesis/uach/2002/fcm645e/doc/fcm645e.pdf.

93. Barrientos M. Estudio cualitativo y cuantitativo de las quinolonas y fluoroquinolonas importadas y autorizadas para uso y disposición en medicina y en veterinaria en Chile, en el período 2002-2005. Consideraciones sobre su impacto para la salud pública y el medio ambiente. Tesis de Grado. Escuela de Química y Farmacia. Universidad Austral de Chile, 2006. http://cybertesis.uach.cl/ tesis/uach/2006/fcb2751e/doc/fcb2751e.pdf.

94. Gómez C. Estudio cualitativo y cuantitativo de las tetraciclinas y fenicoles importados y autorizados para uso y disposición en medicina humana y en veterinaria en Chile, en el período 2000-2007. Consideraciones sobre su impacto para la salud pública y el medio ambiente. Tesis de Grado. Escuela de Química y Farmacia. Universidad Austral de Chile, 2009.

95. Buschmann AH, Riquelme VA, Hernández-González MC, Varela D, Jiménez JE, Henríquez LA, et al. A review of the impacts of salmonid farming on marine coastal ecosystems in the southeast Pacific. ICES J Marine Sci 2006; 63: 1338-45.

96. Buschmann A, Cabello F, Young K, Carvajal J, Varela DA, Henríquez L. Salmon aquaculture and coastal ecosystem health in Chile: Analysis of regulations, environmental impacts and bioremediation systems. Ocean Coastal Management 2009; 52: 243-9.

97. Sapkota A, Sapkota AR, Kucharski M, Burke J, McKenzie $\mathrm{S}$, Walker $\mathrm{P}$, et al. Aquaculture practices and potential human health risks: Current knowledge and future priorities. Environ Int 2008; 34: 1215-26.

98. Silbergeld EK, Graham J, Price LB. Industrial food animal production, antimicrobial resistance, and human health. Annu Rev Public Health 2008; 29: 151-69.

99. Fortt ZA, Cabello FC, Buschmann RA. Residues of tetracycline and quinolones in wild fish living around a salmon aquaculture center in Chile. Rev Chil Infect 2007; 24: 14-8.

100. Robicsek A, Strahilevitz J, Sahm DF, Jacoby GA, Hooper DC. $q n r$ prevalence in ceftazidime-resistant Enterobacteriaceae isolates from the United States. Antimicrob Agents Chemother 2006; 8: 2872-4.

101. Weisburg WG, Barns SM, Pelletier DA, Lane DJ. 16 S ribosomal DNA amplification for phylogenetic study. J Bacteriol 1991; 173: 697-703. 